\title{
Laser Synthesis of Nanometric Iron Oxide Films with High Seebeck Coefficient and High Thermoelectric Figure of Merit
}

\author{
S. A. Mulenko • N. T. Gorbachuk • N. Stefan
}

Accepted: 5 November 2014 / Published online: 19 November 2014

(C) Springer Science+Business Media New York 2014

\begin{abstract}
Radiation of a KrF-laser $(\lambda=248 \mathrm{~nm})$ was used for the synthesis by reactive pulsed laser deposition (RPLD) of nanometric iron oxide $\left[\mathrm{Fe}_{2} \mathrm{O}_{3-\mathrm{X}}(0 \leq x \leq 1)\right]$ films with variable thickness, stoichiometry and electrical properties. Film deposition was carried out on $<100>\mathrm{Si}$ at its temperature to have being increased from 293 to $800 \mathrm{~K}$. XRD analysis showed that films deposited on Si substrate had polycrystalline structure. Films demonstrated semiconductor temperature trend with variable band gap $\mathrm{E}_{\mathrm{g}}$ about $1.0 \mathrm{eV}$ or less depending on oxygen pressure, the number of laser pulses and substrate temperature. Film thickness $(13-60 \mathrm{~nm})$ depended on oxygen pressure, substrate temperature and number of laser pulses. The higher substrate temperature, the more crystallinity of the deposited iron oxides' films was resulting in increasing of thermo electromotive force coefficient (Seebeck coefficient, S). It was found out the optimum oxygen pressure in the reactor, substrate temperature and film thickness when the $\mathrm{S}$ coefficient was high as $12-4 \mathrm{mV} / \mathrm{K}$ in the range $240-330 \mathrm{~K}$. The thermoelectric figure of merit (ZT) was high as 1-6 in the range 280-330 K. This makes nanometric $\mathrm{Fe}_{2} \mathrm{O}_{3-\mathrm{X}}$ films, synthesized by UV photons using RPLD method, an exceptionally strong candidate for effective thermo sensors and thermo converters operating at moderate temperature.
\end{abstract}

Keywords Oxide $\cdot$ Thin films $\cdot$ Laser deposition $\cdot$ Sensor $\cdot$ Thermo converter

\footnotetext{
S. A. Mulenko $(\bowtie)$

Institute for Metal Physics NAS of Ukraine, 36, Academician Vernadsky Blvd., UA-03142 Kiev-142, Ukraine

e-mail: mulenko@ukr.net

N. T. Gorbachuk

Scientifically Technical Enterprise“TDM", Kiev Region, Ukraine

N. Stefan

National Institute for Laser, Plasma and Radiation Physics, PO Box MG-54, RO-77125 Magurele, Romania
} 


\section{Introduction}

At present, great interest is growing up for nanometric films, to test the advantages of reduced thickness on the performances of electronic devices and sensors [1]. As it was shown in our previous works that nanometric films based on transitional metals silicides and oxides synthesized by pulsed laser deposition (PLD), reactive pulsed laser deposition (RPLD) and laser chemical vapour deposition (LCVD) are quite suitable materials for thermo-tenso-photo-chemical sensors [2-8]. These silicides and oxides demonstrated semiconductor properties with band gap $\left(\mathrm{E}_{\mathrm{g}}\right)$ less than $1.0 \mathrm{eV}$. RPLD was applied for the first time to synthesize of nanometric iron oxide films on $<100>\mathrm{Si}$ substrate for thermo-chemical sensors [3]. Also, RPLD was used for the synthesis of nanometric iron oxide films on Si substrate for thermo-photo-chemical sensors [7, 8]. RPLD was applied before for elemental ablation of iron target in low-pressure oxygen to deposit iron oxides' thin films for investigation of their magnetic and optical properties [9]. Most of their properties depend on the band gap value, which in turn, depends on the oxide film stoichiometry and its thickness. It should be mentioned that previous experiments were carried out when film deposition was fulfilled on $\mathrm{Si}$ substrate at room temperature (RT). Nevertheless, it further remains very important to elucidate the influence of substrate nature and its temperature on deposited films' structure, which strongly determines the electrical and optical properties. Therefore, it is very important to investigate crystallization process on thermoelectric properties (i.e. thermo electromotive force coefficient S-Seebeck coefficient and the thermoelectric figure of merit ZT) of iron oxides' films while their deposition on heated Si substrates. A more complete investigation of the structural, electrical and especially thermo sensor and thermo converter characteristics of iron oxide nanometric films deposited on $\mathrm{Si}$ substrate in a wide oxygen pressure $\left(\mathrm{PO}_{2}\right)$ range, at different thickness and substrate temperature $\left(\mathrm{T}_{\mathrm{S}}\right)$ are presented and discussed in this paper.

Some methods were used to deposit iron oxides' films: congruent laser ablation [10], chemical vapour deposition [11], gas phase deposition [12], and electron beam deposition [13]. These methods were used to fabricate films with the stoichiometry $\mathrm{Fe}_{2} \mathrm{O}_{3}$ or $\mathrm{Fe}_{3} \mathrm{O}_{4}$ for their investigation of magnetic properties. RPLD is a quite simple and fast process, since elemental target and low-pressure gases are used. RPLD allows a good control of thickness and stoichiometry of deposits, simply varying the number of laser pulses $(\mathrm{N})$ and the gas pressure in the reactor [14]. On the other hand, there is great interest to the materials with high ZT, as it is connected with energetic problem. For example, nanostructured p-type $\mathrm{PbTe}$ with $\mathrm{ZT} \cong 1.5$ at $773 \mathrm{~K}$ was synthesized with adding thallium as impurity levels [15]. Thin-film thermoelectric materials based on $\mathrm{p}$ type $\mathrm{Bi}_{2} \mathrm{Te}_{3} / \mathrm{Sb}_{2} \mathrm{Te}_{3}$ superlattice demonstrated a significant enhancement of $\mathrm{ZT}$ up to 2.4 in the range $261-325 \mathrm{~K}$ that is important for microelectrothermal systems [16]. Crystalline thin films containing the $\mathrm{Bi}_{2} \mathrm{Te}_{3}$ phase with non-dimensional thermoelectric figure of merit $\mathrm{ZT} \cong 1.0$ at RT were deposited by PLD method [17]. High S coefficient and the thermoelectric figure of merit were obtained in two-dimensional electron gas in $\mathrm{SrTiO}_{3}$ where this $\mathrm{S}$ coefficient was about $0.85 \mathrm{mV} / \mathrm{K}$ and ZT $\equiv 2.4$ [18]. Negative $\mathrm{S}$ coefficient $(-0.4 \mathrm{mV} / \mathrm{K})$ for $\mathrm{PbSe}$ and PbTe bulk was presented in the paper [19]. Unfortunately, all these materials with comparatively high Seebeck coefficient and high thermoelectric figure of merit were synthesized with using toxic atoms such as Te, Sb, $\mathrm{Se}, \mathrm{Pb}, \mathrm{Sr}$. Therefore, the main purpose of this work is to propose laser method for the 
synthesis of thermoelectric materials with high Seebeck coefficient and high thermoelectric figure of merit using non-toxic precursors (i.e. Fe atoms and $\mathrm{O}_{2}$ molecules). Here, we used the RPLD technique, where pure iron atoms were ablated by energetic $\mathrm{KrF}$ laser pulses in low pressure $\mathrm{O}_{2}$ atmosphere $(0.10-1.0 \mathrm{~Pa})$ to obtain nanometric iron oxides' films with high thermoelectric properties

\section{Methods}

Film depositions were carried out in a stainless-steel vacuum reactor. Before each deposition the reactor was evacuated down to a residual pressure of $\sim 4.5 \times 10^{-5} \mathrm{~Pa}$ to avoid contamination. Then, the flux of pure $\mathrm{O}_{2}(99.999 \%)$ was introduced and stabilised to the desired dynamic pressure of $0.1,0.5$ or $1.0 \mathrm{~Pa}$. A pure Fe $(99.5 \%)$ target was ablated with a $\mathrm{KrF}(\lambda=248 \mathrm{~nm})$ excimer laser pulses at a fluence of $4.0 \mathrm{~J} /$ $\mathrm{cm}^{2}$ and frequency repetition rate of $10 \mathrm{~Hz}$. The duration of the pulse was $\sim 25 \mathrm{~ns}$. Each film was deposited by a definite number of laser pulses, namely 4000, 5000 and 6000, depending on oxygen pressure in the deposition reactor. The target was rotated at a frequency of $3 \mathrm{~Hz}$ to avoid piercing and ensure a smooth ablation procedure. Before each deposition, the target surface was cleaned by 3000 laser pulses with a shutter shielding the substrate. Then, the flux of ablated iron atoms were collected on $\mathrm{Si}$ substrates cleaned in an ultrasonic bath with ethylic alcohol and deionised water. Substrates were placed parallel at $45-\mathrm{mm}$ distance from the target. The schematic diagram of the set-up for laser synthesis of nanometric iron oxide films is shown in Fig. 1.

The thickness of deposited films was measured by "Tensor Instruments" model "Alpha-step 100" profilemeter with an error of $5 \%$. The morphology of the deposited films was investigated with electron microscope JEM 2000 FX II. The crystalline structure of deposited films was studied with an X-ray diffractometer (XRD) "Stoe" at $45 \mathrm{kV}$ and $33 \mathrm{~mA}\left(\mathrm{Cu} K_{\alpha}\right.$ radiation). The direct current (DC) electrical resistance of Si substrate with deposited films was measured by two-probe technique. Ohmic contacts were obtained by indium or silver coatings. Temperature dependence of the electrical resistance and specific conductivity $(\sigma)$ of the deposited films, the S coefficient and the thermoelectric figure of merit were studied in the range $230-330 \mathrm{~K}$ with a high

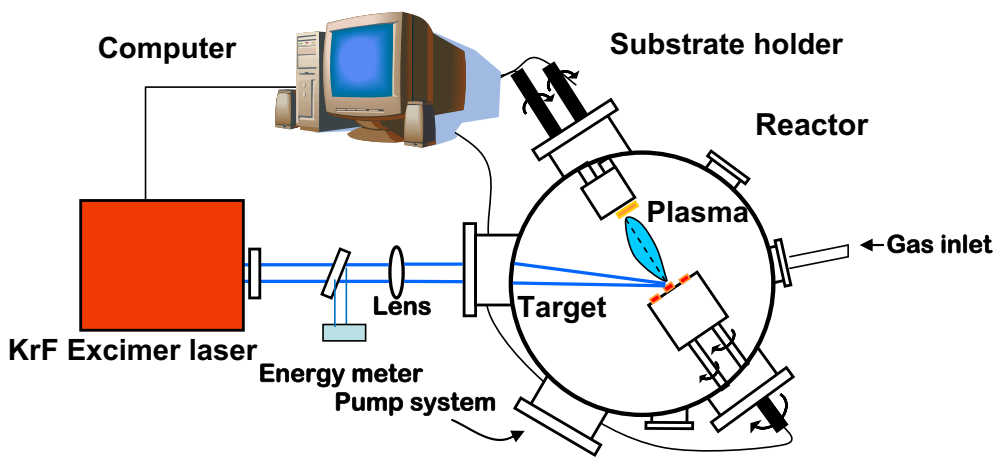

Fig. 1 Schematic diagram of the laser synthesis experimental set-up based on RPLD 
resistance multimeter. Special installation was used for temperature measurement of a sample and temperature difference $(\Delta \mathrm{T})$ between heated and room temperature end or cooled and RT end of the sample. These measurements were carried out by using two thermocouples. The thermo electromotive force (e.m.f.) $(\Delta U)$ was measured between heated and RT end or cooled and RT end of the sample with a high resistance voltmeter. The temperature dependence of the $\mathrm{S}$ coefficient was measured from these data as a ratio of $\Delta \mathrm{U} / \Delta \mathrm{T}$ in the range $230-330 \mathrm{~K}$ after producing thermal gradient along the sample. Calculations of the specific conductivity were performed taking into account film thickness (d) and the geometrical shape of Si substrates with the deposited film $(0.8 \times 0.25) \mathrm{cm}^{2}$.

\section{Results}

Iron oxides with the stoichiometry $\mathrm{Fe}_{2} \mathrm{O}_{3-\mathrm{X}}(0 \leq x \leq 1)$ were deposited in the form of nanometric (i.e. 2D structures) films. The temperature dependence of the specific conductivity $(\sigma)$ of the deposited films demonstrated the typical trend of semiconductor materials which could be described by the well-known expression [20]

$$
\sigma=\sigma_{\mathrm{g}} \exp \left(-E_{\mathrm{g}} / 2 k \mathrm{~T}\right)+\sigma_{\mathrm{i}} \exp \left(-E_{\mathrm{i}} / k \mathrm{~T}\right),
$$

where $\sigma_{\mathrm{g}}$ is the intrinsic conductivity; $\sigma_{\mathrm{i}}$ is the conductivity determined by impurities; $k$ is the Boltzmann constant; $E_{\mathrm{g}}$ is the band gap for intrinsic conductivity and $\mathrm{E}_{\mathrm{i}}$ is the band gap assigned to impurities in the iron oxides (e.g. unreacted iron atoms). In our experimental conditions when $T>(\mathrm{RT})$, the conductivity $\sigma_{\mathrm{g}}$ is governed by the main charge carriers. Therefore, it is possible to calculate $\mathrm{E}_{\mathrm{g}}$ from the following expression:

$$
\mathrm{E}_{\mathrm{g}}=\frac{2 k \ln \left[\sigma\left(T_{1}\right) / \sigma\left(T_{2}\right)\right]}{1 / T_{2}-1 / T_{1}},
$$

where $\sigma\left(\mathrm{T}_{1}\right)$ and $\sigma\left(\mathrm{T}_{2}\right)$ are the specific conductivities at the temperature $\mathrm{T}_{1}$ and $\mathrm{T}_{2}$, accordingly, when $T_{1}>T_{2}$. The temperature dependence of the specific conductivity of the deposited films was measured in the range $280-330 \mathrm{~K}$ to test the semiconductor behaviour of the deposited films.

The morphology of the deposited films was investigated by SEM.

As it is seen, while film deposition on heated Si substrate there are crystal boundaries assigned with crystallization process of iron oxides' films and even some inhomogeneous are on film surface (Fig. 2). But while film deposition was carried out on Si substrate at $293 \mathrm{~K}$ film surface is quite homogeneous. XRD analysis evidenced polycrystalline structure of the films deposited on $\mathrm{Si}$ substrate at $0.1,0.5$ and $1.0 \mathrm{~Pa} \mathrm{O}_{2}$ and at substrate temperature 293, $800 \mathrm{~K}$ (Figs. 3a-f).

These deposits were carried out at 4000, 5000 and 6000 laser pulses, accordingly with increasing oxygen pressure in the reactor. The thickness of films deposited with 4000 laser pulses at these conditions was about 53-60 nm for samples deposited at $0.1 \mathrm{~Pa}$ and decreased to $26-36 \mathrm{~nm}$ for the deposited film at $0.5 \mathrm{~Pa}$ and 5000 laser pulses. The highest pressure of $1.0 \mathrm{~Pa}$ and 6000 laser pulses results in decreasing of film thickness to $13-40 \mathrm{~nm}$. But the more substrate temperature while film deposition, the more film thickness is at the same number of laser pulses and the same oxygen 


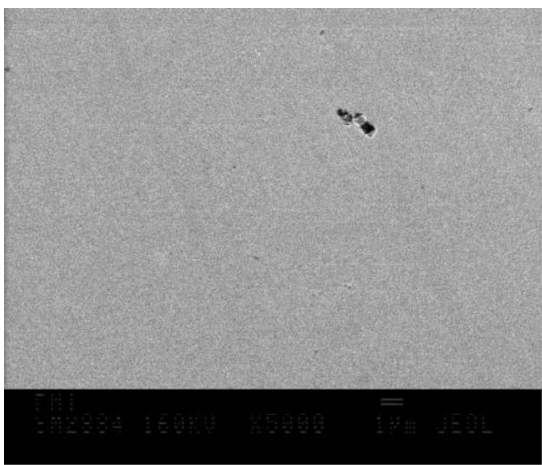

a

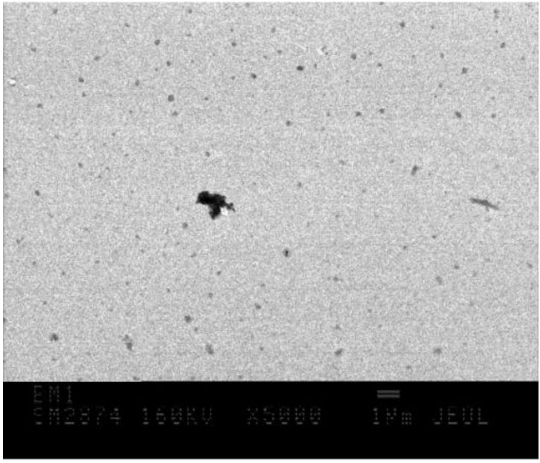

c

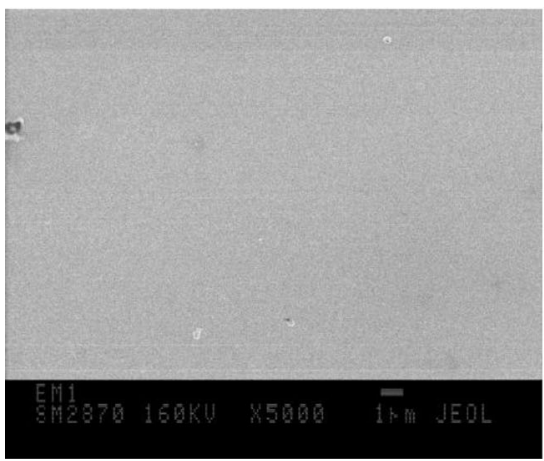

e

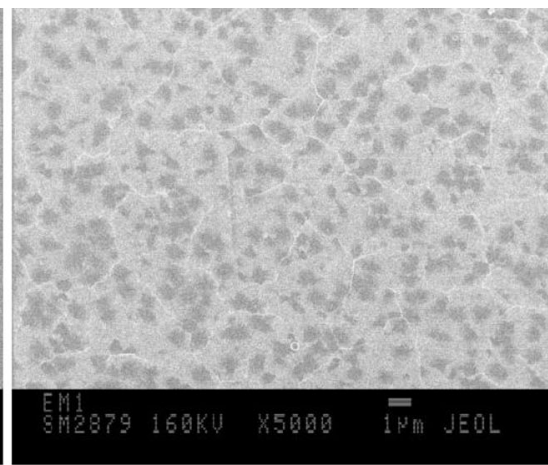

b

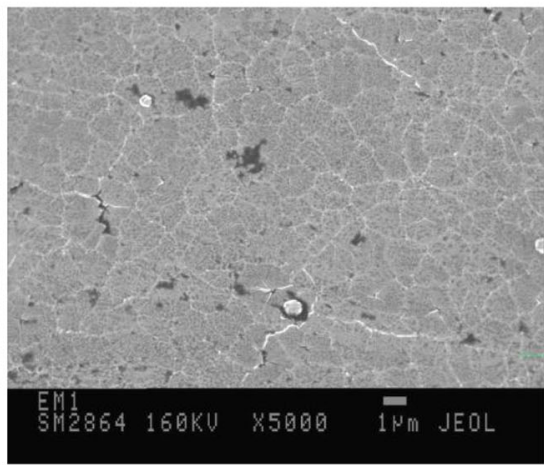

d

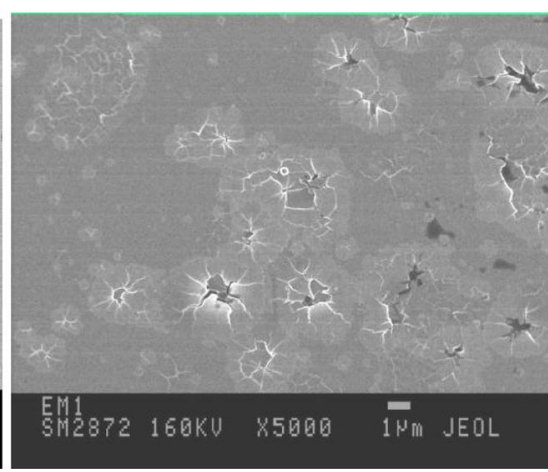

f

Fig. 2 SEM of nanometric iron oxide films deposited on $\mathrm{Si}$ substrate at different conditions: $\mathbf{a}-\mathrm{T}_{\mathrm{S}}=293 \mathrm{~K}$, $d=13 \mathrm{~nm} ; \mathbf{b}-\mathrm{T}_{\mathrm{S}}=800 \mathrm{~K}, d=40 \mathrm{~nm} ; \mathbf{c}-\mathrm{T}_{\mathrm{S}}=293 \mathrm{~K}, d=26 \mathrm{~nm} ; \mathbf{d}-T_{S}=800 \mathrm{~K}, d=36 \mathrm{~nm} ; \mathbf{e}-\mathrm{T}_{\mathrm{S}}=293 \mathrm{~K}, d=$ $53 \mathrm{~nm} ; \mathbf{f}-\mathrm{T}_{\mathrm{S}}=800 \mathrm{~K}, d=60 \mathrm{~nm}$

pressure in the reactor. The more number of laser pulses at the same oxygen pressure and at the same substrate temperature, the more film thickness (Fig. 4).

The specific conductivity of the film deposited at $0.1 \mathrm{~Pa} \mathrm{O}_{2}$ decreased from 112 to $54 \Omega^{-1} \mathrm{~cm}^{-1}$ when temperature decreased from 322 to $293 \mathrm{~K}$. The specific conductivity 

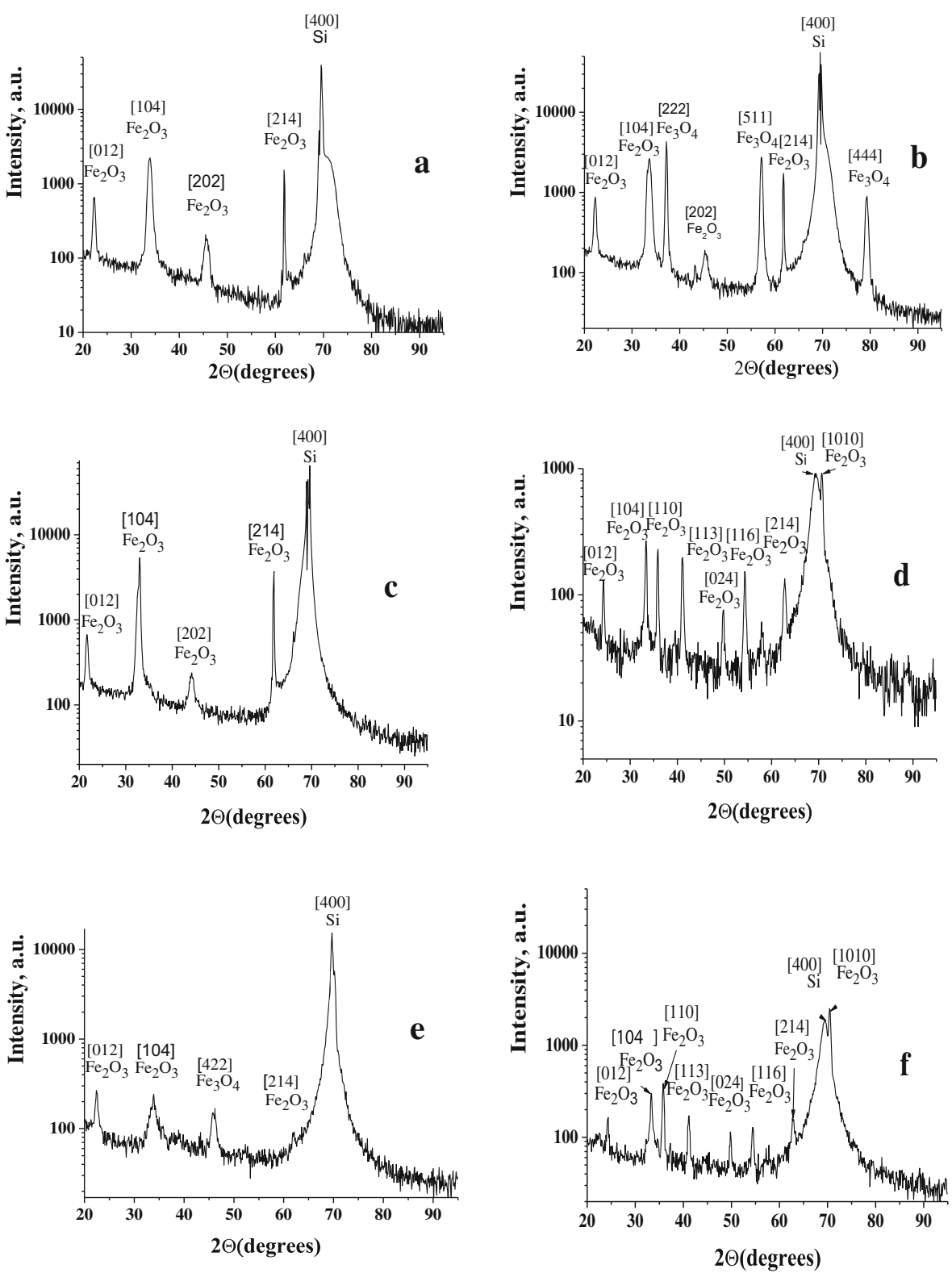

Fig. 3 XRD diagrams of nanometric $\mathrm{Fe}_{2} \mathrm{O}_{3-\mathrm{X}}$ film deposited by RPLD on Si substrate: $\mathbf{a}-\mathrm{T}_{\mathrm{S}}=293 \mathrm{~K}, \mathbf{b}-\mathrm{T}_{S}=$ $800 \mathrm{~K}, \mathrm{PO}_{2}=0.1 \mathrm{~Pa}, N=4000 ; \mathbf{c}-\mathrm{T}_{\mathrm{S}}=293 \mathrm{~K}, \mathbf{d}-\mathrm{T}_{S}=800 \mathrm{~K}, \mathrm{PO}_{2}=0.5 \mathrm{~Pa}, N=5000 ; \mathbf{e}-\mathrm{T}_{\mathrm{S}}=293 \mathrm{~K}, \mathbf{f}-\mathrm{T}_{S}=$ $800 \mathrm{~K}, \mathrm{PO}_{2}=1.0 \mathrm{~Pa}, N=6000$

of the film deposited at $1.0 \mathrm{~Pa} \mathrm{O}_{2}$ decreased from 52.6 to $10.5 \Omega^{-1} \mathrm{~cm}^{-1}$ at the same temperature range. By fitting the experimental values of the expression (2) one can obtain $\mathrm{E}_{\mathrm{g}}$ at different oxygen pressure while the deposition was carried out on $\mathrm{Si}$ substrate at $\mathrm{T}_{\mathrm{S}}=293 \mathrm{~K}: \mathrm{E}_{\mathrm{g}} \cong 0.70 \mathrm{eV}, \mathrm{PO}_{2}=0.1 \mathrm{~Pa} ; \mathrm{E}_{\mathrm{g}} \cong 0.86 \mathrm{eV}, \mathrm{PO}_{2}=0.5 \mathrm{~Pa} ; \mathrm{E}_{\mathrm{g}} \cong$ $0.93 \mathrm{eV}, \mathrm{PO}_{2}=1.0 \mathrm{~Pa}$ (Fig. 5). 


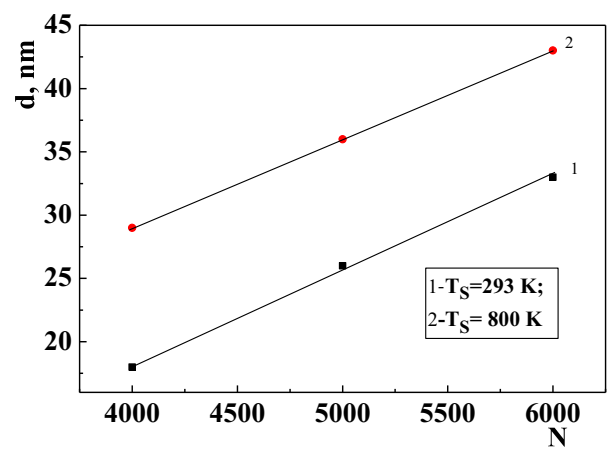

Fig. 4 Film thickness (d) vs. the number of laser pulses at oxygen pressure inside the reactor of $0.5 \mathrm{~Pa}$ and substrate temperature: $1-\mathrm{T}_{\mathrm{S}}=293 \mathrm{~K} ; 2-\mathrm{T}_{\mathrm{S}}=800 \mathrm{~K}$

It means that the films obtained at higher oxygen pressure have more content of higher oxidized phases and, therefore, more content of semiconductor phase in the deposited films, resulting in the increase of the band gap. The temperature dependences of the $\mathrm{S}$ coefficient for nanometric $\mathrm{Fe}_{2} \mathrm{O}_{3-\mathrm{X}}$ film deposited by RPLD on Si substrate surface are presented in Figs. 6 and 7.

Temperature dependences show that the higher temperature of the Si substrate, the higher value of the $\mathrm{S}$ coefficient is in the range $230-330 \mathrm{~K}$. The highest value of the $\mathrm{S}$ coefficient was obtained when deposition was carried out on heated substrate at $T_{\mathrm{S}}=$ $800 \mathrm{~K}$ and oxygen pressure in the reactor of $0.5 \mathrm{~Pa}$ (Fig. 7). Therefore, film deposition was carried on $\mathrm{Si}$ substrate at oxygen pressure of $0.5 \mathrm{~Pa}$ and $\mathrm{T}_{\mathrm{S}}=800 \mathrm{~K}$ at different number of laser pulses (i.e. 4000, 5000 and 6000) to investigate film thickness influence on the $\mathrm{S}$ coefficient. The evaluated band gap of the films deposited at these conditions is the following: $0.44,0.32$ and $0.62 \mathrm{eV}$ with uncertainty of about $10 \%$. Temperature dependences of the $\mathrm{S}$ coefficient for films deposited at different substrate temperature, $N=5000$ and oxygen pressure in the reactor of $0.5 \mathrm{~Pa}$, as optimum parameters, were investigated too (Fig. 8).

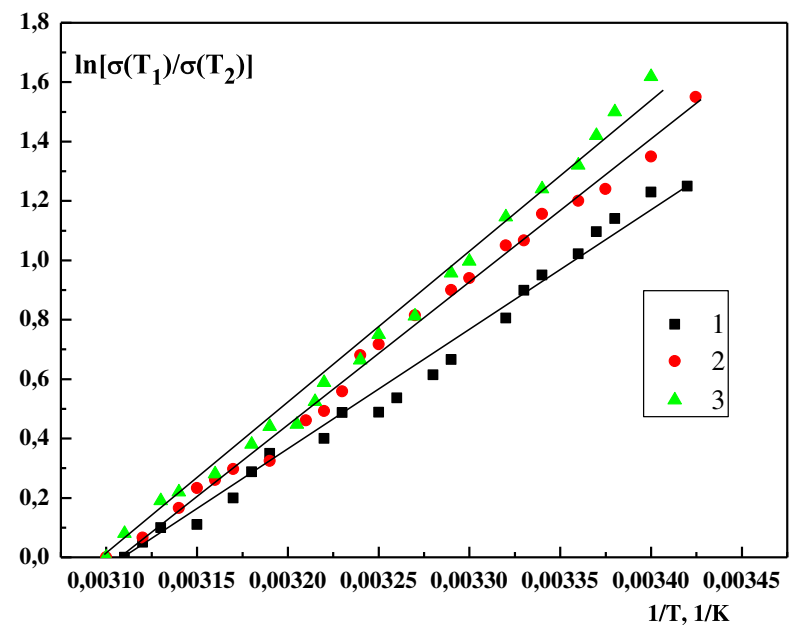

Fig. 5 Arrhenius plot of $\ln \left[\sigma\left(\mathrm{T}_{1}\right) / \sigma\left(\mathrm{T}_{2}\right)\right]$ vs.1/T: $1-\mathrm{E}_{\mathrm{g}} \cong 0.70 \mathrm{eV}, \mathrm{PO}_{2}=0.1 \mathrm{~Pa} ; 2-\mathrm{E}_{\mathrm{g}} \cong 0.86 \mathrm{eV}, \mathrm{PO}_{2}=0.5 \mathrm{~Pa}$; $3-\mathrm{E}_{\mathrm{g}} \cong 0.93 \mathrm{eV}, \mathrm{PO}_{2}=1.0 \mathrm{~Pa} ; \mathrm{T}_{\mathrm{S}}=293 \mathrm{~K} ; \mathrm{N}=4000$ 


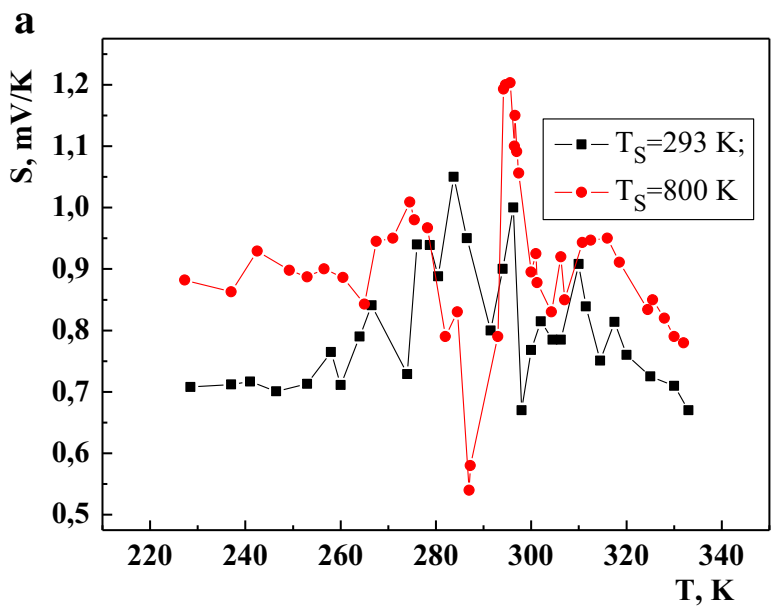

b

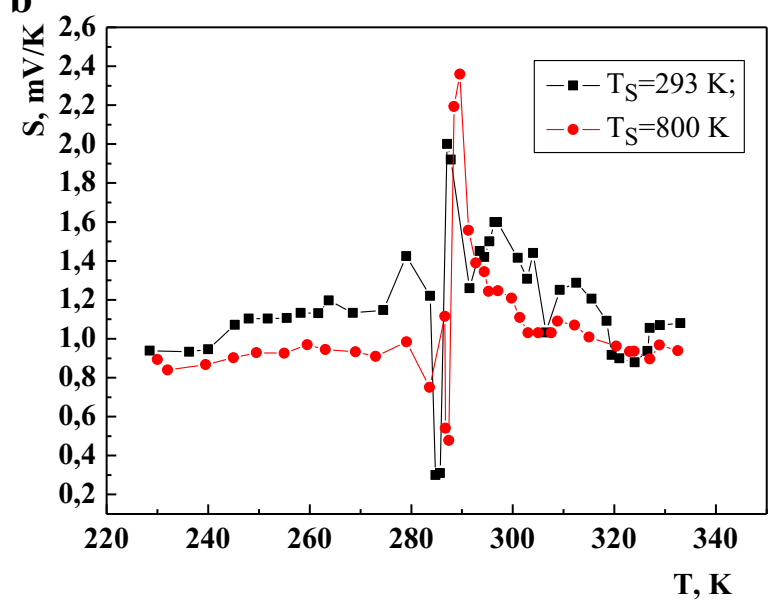

C

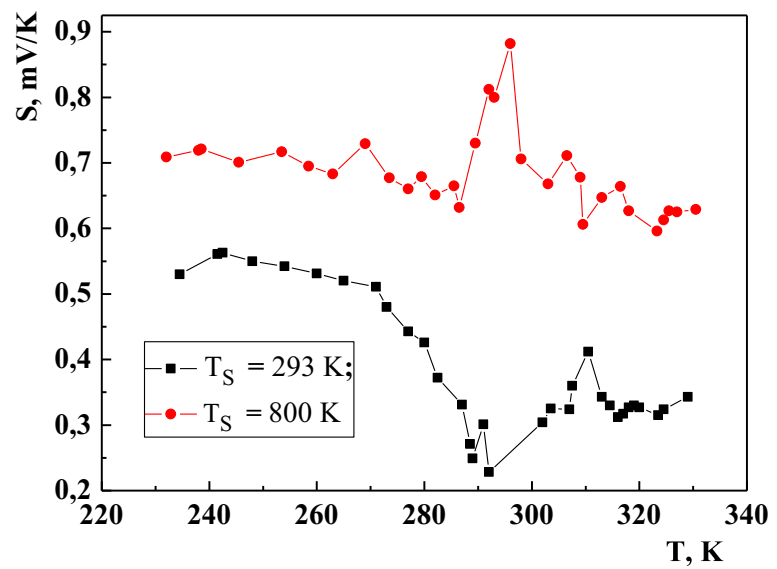

Fig. 6 Thermo electromotive force (e.m.f.) coefficient $\mathrm{S}$ vs. temperature for nanometric iron oxide films deposited by RPLD on Si substrate at oxygen pressure inside the reactor: $\mathbf{a}-\mathrm{PO}_{2}=0.1 \mathrm{~Pa}, N=4000$ at $\mathrm{T}_{\mathrm{S}}=293$ and $800 \mathrm{~K} ; \mathbf{b}-\mathrm{PO}_{2}=0.5 \mathrm{~Pa}, N=4000$ at $\mathrm{T}_{\mathrm{S}}=293$ and $800 \mathrm{~K}$; $\mathbf{c}-\mathrm{PO}_{2}=1.0 \mathrm{~Pa}, N=6000$ at $\mathrm{T}_{\mathrm{S}}=293$ and $800 \mathrm{~K}$ 


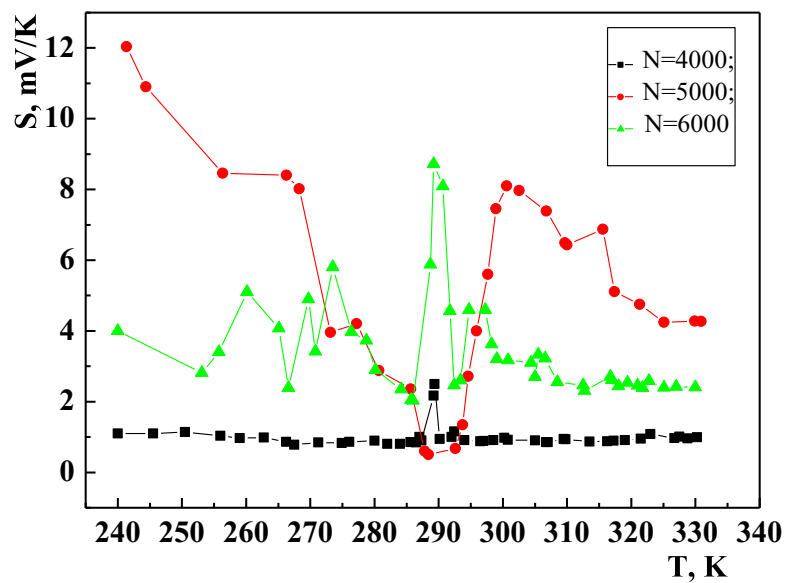

Fig. 7 Thermo electromotive force (e.m.f.) coefficient $\mathrm{S}$ vs. temperature for nanometric iron oxide films deposited by RPLD on Si substrate at oxygen pressure inside the reactor: $\mathrm{PO}_{2}=0.5 \mathrm{~Pa} ; \mathrm{T}_{\mathrm{S}}=800 \mathrm{~K} ; N=4000$, 5000,6000

It was found out optimum conditions to obtain high value of the $\mathrm{S}$ coefficient for nanometric $\mathrm{Fe}_{2} \mathrm{O}_{3-\mathrm{X}}(0 \leq x \leq 1)$ films (i.e. $\mathrm{PO}_{2}=0.5 \mathrm{~Pa}, \mathrm{~T}_{\mathrm{S}}=800 \mathrm{~K}, d \cong 36 \mathrm{~nm}$ ). Measurement method of the $\mathrm{S}$ coefficient is such as the uncertainty in determining of its value is no more than $2 \%$ in the temperature range $310 \leq \mathrm{T} \leq 290 \mathrm{~K}$. But this method demonstrates uncertainty about $10 \%$ in determining of the $\mathrm{S}$ coefficient in the temperature range $290 \leq \mathrm{T} \leq 310 \mathrm{~K}$, as error in a measurement of temperature difference in this range is sufficiently higher than in the temperature range $310 \leq \mathrm{T} \leq 290 \mathrm{~K}$. These measurements of the $\mathrm{S}$ coefficient were carried out no less than for three samples with identical film. Identical film is the film deposited at the same oxygen pressure, substrate temperature and number of laser pulses. The data of nanometric $\mathrm{Fe}_{2} \mathrm{O}_{3-\mathrm{X}}(0 \leq x \leq 1)$ films deposited by RPLD at different experimental conditions are presented in Table 1.

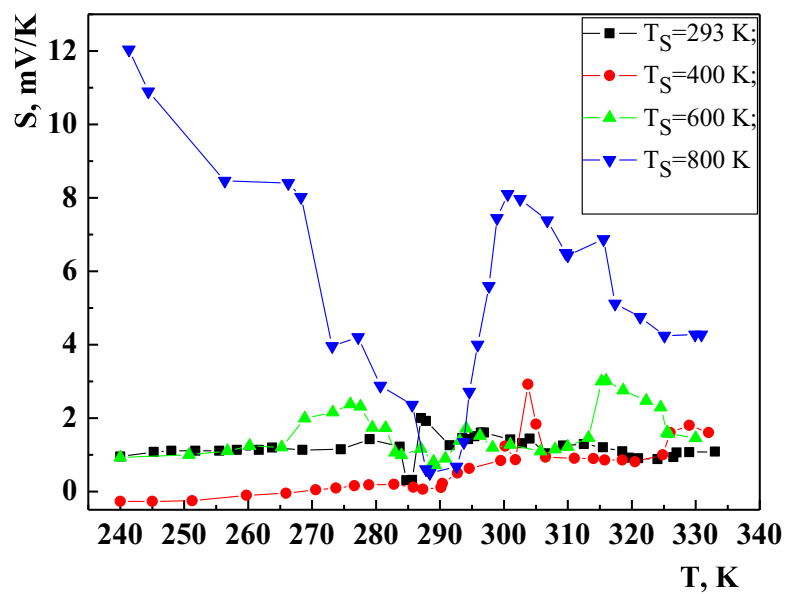

Fig. 8 Thermo electromotive force (e.m.f.) coefficient $\mathrm{S}$ vs. temperature for nanometric iron oxide films deposited by RPLD on Si substrate at oxygen pressure inside the reactor: $\mathrm{PO}_{2}=0.5 \mathrm{~Pa} ; N=5000 ; \mathrm{T}_{\mathrm{S}}=293,400$, 600 , and $800 \mathrm{~K}$ 
Table 1 The data of nanometric $\mathrm{Fe}_{2} \mathrm{O}_{3-\mathrm{X}}(0 \leq \mathrm{x} \leq 1)$ films deposited by RPLD

\begin{tabular}{lllll}
\hline $\begin{array}{l}\text { Oxygen } \\
\text { pressure in the } \\
\text { reactor }(\mathrm{Pa})\end{array}$ & $\begin{array}{l}\text { Film thickness } \\
\mathrm{d}(\mathrm{nm})\end{array}$ & $\begin{array}{l}\text { Substrate } \\
\text { temperature }\left(\mathrm{T}_{\mathrm{S}}\right)\end{array}$ & $\begin{array}{l}\text { Energy band } \\
\text { gap Eg }(\mathrm{eV})\end{array}$ & $\begin{array}{l}\text { Thermo e.m.f. Smax. } \\
\left(\mathrm{mVK}^{-1}\right) \text { in the } \\
\text { range 240-330 K }\end{array}$ \\
\hline 0.10 & 53 & 293 & 0.76 & 1.05 \\
0.10 & 60 & 800 & 1.18 & 1.20 \\
0.50 & 26 & 293 & 0.86 & 2.00 \\
0.50 & 29 & 800 & 0.44 & 2.30 \\
0.50 & 36 & 800 & 0.32 & 12.0 \\
0.50 & 43 & 800 & 0.62 & 8.80 \\
1.00 & 13 & 293 & 0.93 & 0.55 \\
1.00 & 40 & 800 & 0.71 & 0.86 \\
\hline
\end{tabular}

The thermoelectric figure of merit is a parameter to characterize thermoelectric properties of materials as a possibility of their application for thermo converters. The thermoelectric figure of merit is known to be determined by the following expression:

$$
Z T=\frac{\sigma(S)^{2} T}{\chi}
$$

where $\sigma$ is the specific conductivity of the deposited film; $\mathrm{S}$ is Seebeck coefficient; $\mathrm{T}$ is film temperature; $\chi$ is thermo conductivity coefficient $(\chi=0.84 \mathrm{~W} / \mathrm{cm} \mathrm{K}$ for Si substrate as it is higher than for iron oxides [21]). The value of ZT was obtained taking into account the temperature dependences of the $\mathrm{S}$ coefficient at the following conditions: $\mathrm{PO}_{2}=0.5 \mathrm{~Pa}, \mathrm{~T}_{\mathrm{S}}=800 \mathrm{~K}$ and $N=4000,5000,6000$ when this coefficient is higher than at other conditions (Fig. 7). The temperature dependences of the specific conductivity at these conditions are presented in Fig. 9. As it is seen from the expression (3), to obtain high ZT it is needed to have high $\mathrm{S}$ coefficient and high $\sigma$ and $\chi$ should be low as it is possible.

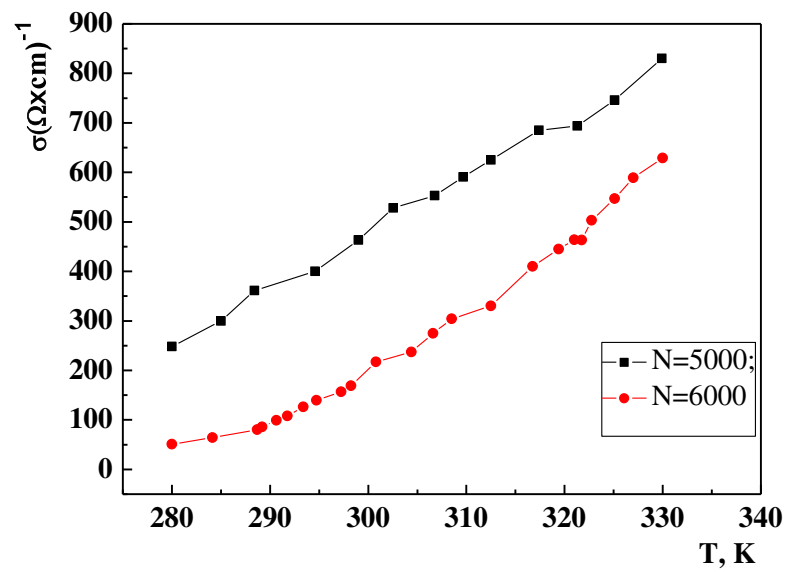

Fig. 9 Temperature dependences of the specific conductivity of nanometric iron oxide film deposited by RPLD on $\mathrm{Si}$ substrate at $\mathrm{PO}_{2}=0.5 \mathrm{~Pa} ; \mathrm{T}_{\mathrm{S}}=800 \mathrm{~K} ; N=5000,6000$ 
To this end, temperature dependences of ZT for the highest values of the $\mathrm{S}$ coefficient are presented in Fig. 10.

\section{Discussions}

The experimental data show that the band gap $\mathrm{E}_{\mathrm{g}}$ of the semiconductor films deposited on Si substrate at $293 \mathrm{~K}$ by RPLD is being increased with increasing oxygen pressure from 0.1 up to $1.0 \mathrm{~Pa}$, due to the higher content of iron oxides with higher oxidized phases. Oxygen contribution in the deposited films comes out from homogeneous and heterogeneous reactions between iron atoms and oxygen molecules in the volume above substrate surface and on its surface during film growth.

The increase of oxygen pressure in the reactor resulted in decreasing of line intensity in XRD iron oxides' diagrams due to the decrease of crystalline status in deposited films, as the increase of oxygen pressure caused a kinetic energy loss of iron atoms and their ions owing to increasing of collision frequency with oxygen molecules. Correspondingly, the cooling time of films on a substrate decreases and the crystallization status is worsening (Fig. 3a, c and e). On the other hand, in the case of substrates temperature of $800 \mathrm{~K}$, the number of the iron oxide lines in XRD diagram are enhanced (Fig. 3b, d and f), as the kinetic energy of iron atoms, their ions and cooling time are increased resulting in the growth of a more amount of $\mathrm{Fe}_{2} \mathrm{O}_{3-\mathrm{X}}$ semiconductor phases in the deposited films. The increase substrate temperature resulted in the increasing of $\sigma$ value owing to higher crystalline phase's content. So the more substrate temperature, the more new iron oxide phases appear in the deposited films owing to more kinetic energy for the formation these new phases in the comparison with $293 \mathrm{~K}$ substrate temperature.

The $\mathrm{S}$ coefficient is important for studying kinetic phenomena of charge transfer in materials [1]. To this purpose, it is necessary to know besides the correlation between the temperature and the specific conductivity, the correlation between the temperature and the $\mathrm{S}$ coefficient should be studied. If one takes into account the expressions for

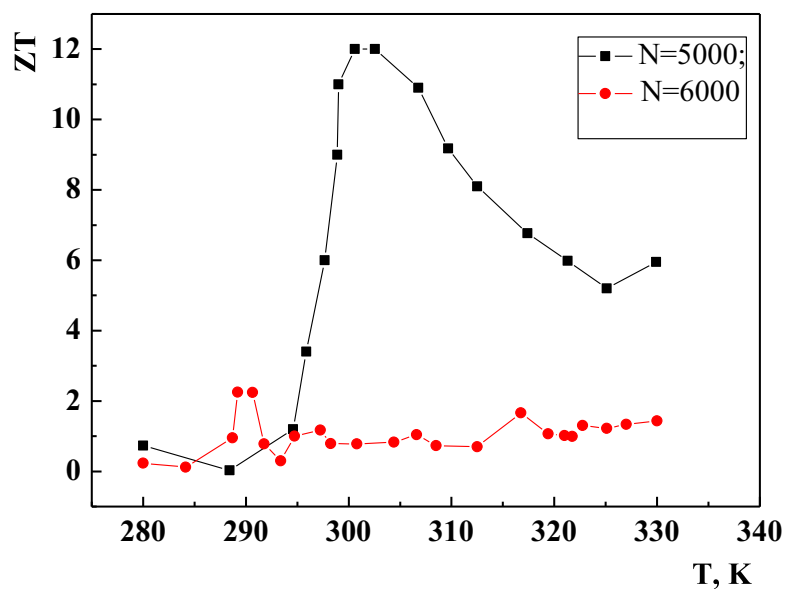

Fig. 10 The thermoelectric figure of merit vs. temperature for nanometric $\mathrm{Fe}_{2} \mathrm{O}_{3-\mathrm{X}}(0 \leq x \leq 1)$ films deposited by RPLD on Si substrate at $\mathrm{PO}_{2}=0.5 \mathrm{~Pa} ; \mathrm{T}_{\mathrm{S}}=800 \mathrm{~K} ; N=5000,6000$ 
electron and hole concentrations in a non-degenerate semiconductor, it is possible to express the $\mathrm{S}$ coefficient in the following form [22]

$$
\mathrm{S}=-\frac{k}{e}\left\{\frac{\left[2+\ln \left(N_{c} / n\right)\right] n \mu_{n}-\left[2+\ln \left(N_{v} / p\right)\right] p \mu_{p}}{n \mu_{n}+p \mu_{p}}\right\},
$$

where $k$ is the Boltzmann constant; $e$ is electron charge; $n, p$ are electron and hole concentrations; $N_{c}, N_{v}$ are effective density-of-states in the conduction and valence bands, respectively; and $\mu_{n}, \mu_{p}$ are electron and hole mobility, respectively. It is seen that the thermo e.m.f. coefficient of semiconductor materials is determined with two parts (i.e. electron and holes) (4). The S coefficient has different maximum values for various films deposited on Si substrates (Figs. 6, 7 and 8) and its values vary with substrate temperature. This non-uniform variation of the $\mathrm{S}$ coefficient can be explained by oscillation of the density-of-states for valance and conduction bands and for impurity levels too. As it is known, there are quantum dimension effects in nanometric semiconductor films with narrow band gap [23]. As it is follow from quasi-pulse periodic Karman-Born conditions where effective density of $N_{c}$ and $N_{v}$ states in two dimensional zone is proportional to effective mass of free charge carriers and equal for film surface unit

$$
N_{S}=\frac{m_{p}^{*}}{h^{2}},
$$

where $m_{p}^{*}$ is effective mass of free charge carriers in film plate; $h$ is Plank constant. Density of $N_{c}$ and $N_{v}$ states in two dimensional zone evaluated for film volume unit is the following:

$$
N_{V}=\frac{m_{p}^{*}}{h^{2} d}
$$

where $\mathrm{d}$ is film thickness. Therefore, $N_{c}$ and $N_{v}$ oscillations occur owing to effective mass change of free charge carriers while film temperature change [24]. As it is seen from the expression (6), the more film thickness, the less effective density-of-states in the conduction and valence bands result in decreasing of the S coefficient. Increasing or decreasing of charge carriers' concentration is not constant with increasing or decreasing substrate temperature as there is the saturation of these concentrations on the states for valance and conductive bands and for impurity levels at definite temperature difference. Additional temperature increasing is a cause of additional increasing of charge carriers' concentration owing to their transition on higher energy levels at higher temperature. This oscillation is being appeared during sample heating. The observed different values of the $\mathrm{S}$ coefficient confirm that semiconductor films consist of iron atoms with different degrees of oxidation result in different value of $E_{g}$. While temperature changing in the comparison with the sample end at RT, there is changing of charge carriers' concentration (i.e. $n$ and $p$-type carriers). Semiconductor properties of the deposited films are assigned with crystalline semiconductor $\mathrm{Fe}_{2} \mathrm{O}_{3}$ and $\mathrm{Fe}_{3} \mathrm{O}_{4}$ phases' content in the deposited films (Fig. 3a-f). It is known that rate constant of chemical reaction depends on gas pressure and the reaction temperature. Therefore, oxygen pressure in the reactor of $0.5 \mathrm{~Pa}$ and substrate temperature of $800 \mathrm{~K}$ are optimum conditions result in increasing of crystalline semiconductor $\mathrm{Fe}_{2} \mathrm{O}_{3}$ phases' 
content in the deposited films (Fig. 3d). Iron atoms are in different degrees of oxidation in these semiconductor phases (i.e. 2 and 3 oxidation degrees of Fe atoms). As it is seen from XRD analysis, there is different concentration of these semiconductor phases. It should be taken into account that each semiconductor phase has its own value Eg. There are two factors which influence upon band gap value of nanometric iron oxide films. Namely, the increasing oxygen pressure at $T_{s}=293 \mathrm{~K}$ results in $E_{g}$ increasing owing to increasing the higher content of iron oxides in the deposited films with higher oxidized phases. On the other hand, the decreasing $\mathrm{E}_{\mathrm{g}}$ value while the deposition on heated substrate in comparison with the deposition on the substrate at $293 \mathrm{~K}$ and oxygen pressure more than $0.1 \mathrm{~Pa}$ can be explained by the appearance of semiconductor phases having less $\mathrm{E}_{\mathrm{g}}$ values (Table 1). Equivalent total Eg of mixture oxides with different Eg depends on concentration of each semiconductor phase synthesized at definite conditions (i.e. oxygen pressure, substrate temperature, film thickness). Therefore, the value of the $\mathrm{S}$ coefficient is strongly depended not only on film thickness but on equivalent total Eg of oxides' mixture (Figs. 6a-c, 7 and 8, Table 1). As it is seen , the $\mathrm{S}$ coefficient is highest for $36 \mathrm{~nm}$ film deposited on heated substrate at $\mathrm{PO}_{2}=0.5 \mathrm{~Pa}$ as this film consists of semiconductor iron oxides' phases with lowest equivalent total $\mathrm{E}_{\mathrm{g}}$ value in comparison with other films deposited on heated substrate. As the $\mathrm{S}$ coefficient is positive in all measured temperature range, $p$ - type of charge carriers prevails above $n$ - type of charge carriers in these iron oxide films. It was found out the optimum oxygen pressure $\left(\mathrm{PO}_{2}=0.5 \mathrm{~Pa}\right)$ and substrate temperature $\left(\mathrm{T}_{\mathrm{S}}=800 \mathrm{~K}\right)$ when the $\mathrm{S}$ coefficient is high as $12-4 \mathrm{mV} / \mathrm{K}$ in the range $240-330 \mathrm{~K}$ (Fig. 8).

Nanometric $\mathrm{Fe}_{2} \mathrm{O}_{3-\mathrm{X}}(0 \leq x \leq 1)$ films demonstrated high thermoelectric figure of merit, especially for film with high S coefficient. The highest obtained ZT is varied from 1 to 6 in the range $280-330 \mathrm{~K}$ with the maximum of 12 at 300-304 K (Fig. 10). In general, for polycrystalline thin films, increasing of ZT should be due to the dropping of the thermo conductivity coefficient, increasing of the $\mathrm{S}$ coefficient and increasing of the $\sigma$ while temperature increasing. It should be noted that there are two parts in the thermo conductivity coefficient which is assigned with electron part and lattice part $\left(\chi=\chi_{e}+\chi_{l}\right)$. From the Wiedemann-Franz law for free electrons $\chi_{e}$ has the following expression:

$$
\chi_{e}=L \sigma T
$$

where $\mathrm{L}$ is the Lorenz factor for free electrons $\left(L=2.445 \times 10^{-8} \mathrm{~W} \Omega / \mathrm{K}^{2}\right)$. Thermo conductivity coefficient dropping is caused by phonon scattering at grain boundaries and phonon-electron, phonon-phonon scattering while temperature increasing [25]. In spite of the dropping of this coefficient for $\mathrm{Fe}_{2} \mathrm{O}_{3-\mathrm{X}}$ film while film heating, there is no essential effect for the enhance of ZT as iron oxide film is in good thermal contact with $\mathrm{Si}$ substrate, which has sufficiently higher thermo conductivity coefficient than its value for iron oxide film. So (36-43) $\mathrm{nm} \mathrm{Fe}_{2} \mathrm{O}_{3-\mathrm{X}}$ films are shunted by $\mathrm{Si}$ substrate in the sense of thermal conductivity in this case. Therefore, thermal conductivity of such structure (i.e. $\mathrm{Fe}_{2} \mathrm{O}_{3-\mathrm{X}} / \mathrm{Si}$ ) is mainly determined by thermal conductivity of $\mathrm{Si}$ substrate. So using thermo conductivity coefficient for $\mathrm{Si}$ in the evaluation of ZT in this case is grounded because it has the highest influence on charge carriers' gradient in semiconductor polycrystalline nanometric iron oxide film deposited at optimum conditions (i.e. $\mathrm{T}_{\mathrm{S}}=800 \mathrm{~K}, \mathrm{PO}_{2}=0.5 \mathrm{~Pa}$ and $d \cong 36 \mathrm{~nm}$ ). Therefore, ZT is high as its value depends upon high value of the $\mathrm{S}$ coefficient and high value of $\sigma$ in the range $280-330 \mathrm{~K}$. 


\section{Conclusions}

The presented results show that RPLD can be used to produce iron oxide films with variable thickness, degree of iron atom oxidation and, consequently, with different band gap values $\mathrm{E}_{\mathrm{g}}$.. Iron oxide films demonstrated high $\mathrm{S}$ coefficient values while deposition on crystalline and heated $\mathrm{Si}$ substrate. The $\mathrm{S}$ coefficient and the thermoelectric figure of merit for nanometric $\mathrm{Fe}_{2} \mathrm{O}_{3-\mathrm{X}}(0 \leq x \leq 1)$ films deposited by RPLD demonstrated essentially higher values in comparison with other bulk or nanometric film of thermoelectric materials. Optimum conditions were found out when the $\mathrm{S}$ coefficient and the thermoelectric figure of merit are the highest for nanometric $\mathrm{Fe}_{2} \mathrm{O}_{3-\mathrm{X}}$ films in these experimental conditions. Obtained S coefficient for nanometric iron oxides' films is high as $12-4 \mathrm{mV} / \mathrm{K}$ in the range $240-330 \mathrm{~K}$ and $\mathrm{ZT}$ is high as $1-6$ in the range 280 $330 \mathrm{~K}$. These values strongly depend on deposition conditions, namely, oxygen pressure in the reactor, substrate temperature and the number of laser pulses (i.e. film thickness). Moreover, non-toxic atoms are used in proposed technology in comparison with other technologies based on using toxic atoms. It should be concluded that nanometric iron oxide films with polycrystalline structure synthesized by UV photons using RPLD method, which is based on non-toxic technology, are up-to-date materials for effective thermo sensors and thermo converters operating at moderate temperature.

Acknowledgments This work is financial supported within the competitive project of "Fundamental Problems of Nanostructured Systems, Nanomaterials, Nanotechnologies" (15/13-H, 15/14-H) of National Academy of Sciences of Ukraine. The support of National Academy of Sciences of Ukraine and Romanian Academy is acknowledged in the frame of the theme "Synthesis of nanostructured materials and their application for sensors".

\section{References}

1. Nalwa, H.S.: Handbook of nanostructured materials and nanotechnology, vol. 1-5. Academic, San Diego (2000)

2. Caricato, A.P., Luches, A., Romano, F., Mulenko, S.A., Kudryavtsev, Y.V., Gorbachuk, N.T., Fotakis, C., Papadopoulou, E.L., Klini, R.: Deposition of thin films for sensors by pulsed laser ablation of iron and chromium silicide targets. Appl Surf Sci 254, 1288-1291 (2007)

3. Caricato, A.P., Gorbachuk, N.T., Korduban, A.M., Leggieri, G., Luches, A., Mengucci, P., Mulenko, S.A., Valerini, D.: Structural, electrical, and optical characterizations of laser deposited nanometric iron oxide films. J Vac Sci Technol B 28(2), 295-300 (2010)

4. Caricato, A.P., Luches, A., Martino, M., Valerini, D., Kudryavtsev, Y.V., Korduban, A.M., Mulenko, S.A., Gorbachuk, N.T.: Deposition of chromium oxide thin films with large thermoelectromotive force coefficient by reactive pulsed laser ablation. J Optoelectron Adv Mater 12, 427-431 (2010)

5. Mulenko, S.A., Mygashko, V.P.: Laser synthesis of nanostructures based on transition metal oxide. Appl Surf Sci 252, 4449-4452 (2006)

6. Caricato, A.P., Kudryavtsev, Y.V., Leggiery, G., Luches, A., Mulenko, S.A.: Laser deposition of semiconductor thin films based on iron oxides. J Phys D Appl Phys 40, 4866-4871 (2007)

7. Mulenko, S.A., Gorbachuk, N.T.: Synthesis of nanometric iron oxide films by RPLD and LCVD for thermo-photo sensors. Appl Phys B 105, 517-523 (2011)

8. Mulenko, S.A., Petrov, Y.N., Gorbachuk, N.T.: Photon synthesis of iron oxide thin films for thermophoto-chemical sensors. Appl Surf Sci 258, 9186-9191 (2012)

9. Ilievski, F., Tepper, T., Ross, C.A.: Optical and magnetic properties of $\gamma$-iron oxide made by reactive pulsed laser deposition. IEEE Trans Magn 39, 3172-3174 (2003)

10. Tepper, T., Ross, C.A.: Pulsed laser deposition of iron oxide films. J Appl Phys 91, 4453-4456 (2002) 
11. Maruyama, T., Shinyashiki, Y.: Iron-iron oxide composite thin films prepared by chemical vapour deposition from iron pentacarbonyl. Thin Solid Films 333, 203-206 (1998)

12. Shalini, K., Subbanna, G.N., Chandrasekaran, Shivashankar, S.A.: Thin films of iron oxide by low pressure MOCVD using a novel precursor: tris (t-butil-3 oxobutano) iron (III). Thin Solid Films 424, 56-60 (2003)

13. Jain, S., Adeyeye, A.O., Chan, S.Y., Boothroyd, C.B.: Interface properties of iron oxide films. J Phys D Appl Phys 37, 2720-2725 (2004)

14. Hermann, J., Thomann, A.L., Boulmer-Leborgne, C., DeGiorgi, M.L., Perrone, A., Luches, A., Mihailescu, I.N.: Plasma diagnostics in pulsed laser TiN layer deposition. J Appl Phys 77, 2928-2936 (1995)

15. Heremans, J.P., Jovovic, V., Toberer, E.S., Saramat, A., Kurosaki, K., Charoenphakdee, A., Yamanaka, S., Snyder, G.J.: Enhancement of thermoelectric efficiency in PbTe by distortion of the electronic density of States. Science 321, 554-557 (2008)

16. Venkatasubramanian, R., Siivola, E., Colpitts, T., O’Quinn, B.: Thin-film thermoelectric devices with high room-temperature figures of merit. Nature 413, 597-602 (2001)

17. Bailini, A., Donati, F., Zemboni, M., Russo, V., Passoni, M., Casari, C.S., LiBassi, A., Bottani, C.E.: Pulsed laser deposition of $\mathrm{Bi}_{2} \mathrm{Te}_{3}$ thermoelectric films. Appl Surf Sci 254, 1249-1254 (2007)

18. Ohta, H., Kim, S., Mune, Y., Mizoguchi, T., Nomura, K., Ohta, S., Nomura, T., Nakanishi, Y., Ikuhara, Y., Hirano, M., Hosono, H., Koumoto, K.: Giant thermoelectric seebeck coefficient of a two-dimensional electron gas in $\mathrm{SrTiO}_{3}$. Nat Mater 6, 129-134 (2007)

19. Ishida, A., Cao, D., Morioka, S., Inoue, Y., Kita, T.: Seebeck effect in IV-VI semiconductor films and quantum wells. J Electron Mater 38, 940-943 (2009)

20. Wert, C.A., Thomson, R.M.: Physics of Solids, McGraw-Hill Book Company, New York, San FranciscoToronto-London, 556(1964)

21. Kaye, G.W.C., and Laby, T.H.: Tables of physical and chemical constants and some mathematical functions, Longmans, Green and Co, London, New York (1921)

22. Shalimova, K.V.: Fizica Poluprovodnikov, 3rd edn, pp. 177-181. Energoatomizdat, Moskva (1985) (in Russian)

23. Kiselev, V.F., Kozlov, S.N., Zoteev, A.V.: Osnovi fiziki poverhnosti tverdogo tela, pp. 40-43. Moskovski Universitet, Russian (1999)

24. Frederiks, H.P.R., Thurber, W.R., Hosler, W.R.: Electronic transport in strontium titanate. Phys Rev 134, A442-A445 (1964)

25. Saramat, A., Svensson, G., Palmqvist, A.E.C., Stiewe, C., Mueller, E., Platzek, D., Williams, S.G.K., Rowe, D.M., Bryan, J.D., Stucky, G.D.: Large thermoelectric figure of merit at high temperature in Czochralski-grown clathrate $\mathrm{Ba}_{8} \mathrm{Ga}_{16} \mathrm{Ge}_{30}$. J Appl Phys 99, 023708-1-023708-5 (2006) 